\title{
AVALIAÇÃO HIERÁRQUICA DA INFLUÊNCIA DO PAÍS, SETOR E EMPRESA NA EVIDENCIAÇÃO DA RESPONSABILIDADE SOCIAL CORPORATIVA
}

\author{
Rômulo Alves Soares 1 \\ Mônica Cavalcanti Sá de Abreu 2 \\ Pedro de Barros Leal Pinheiro Marino ${ }^{3}$ \\ Silvia Maria Dias Pedro Rebouças ${ }^{4}$
}

- Artigo recebido em: 04/05/2017 •- Artigo aceito em: 28/08/2018 -" Segunda versão aceita em: 29/08/2018

\section{RESUMO}

O estudo realiza uma avaliação hierárquica da influência do sistema nacional de negócios (SNN), setor industrial e fatores associados ao desempenho financeiro da empresa na evidenciação de responsabilidade social corporativa (RSC). Adota-se os pressupostos da teoria institucional para investigar a influência do sistema nacional de negócios na evidenciação de práticas sociais e ambientais em empresas provenientes dos setores de materiais básicos, de operações de petróleo e gás e de utilidade pública. O estudo analisa 264 observações provenientes de empresas que possuem ações negociadas nas bolsas de valores do Brasil (BM\&FBovespa) e do Canadá (Toronto Stock Exchange). Foi realizado um estudo longitudinal, adotando-se estatística descritiva e estimação econométrica com modelo hierárquico. Os resultados indicam que o percentual da variância da evidenciação de RSC é explicada pelo nível do SNN, seguido dos fatores associados ao desempenho financeiro das empresas. A pesquisa reforça a necessidade de os gestores avaliarem as características que moldam o sistema nacional de negócios ao estabelecerem suas estratégias relacionadas à evidenciação de responsabilidade social corporativa.

1 Doutorando em Administração e Controladoria pela Universidade Federal do Ceará. Endereço: Avenida da Universidade, 2470 - Benfica - CEP 60020-180 - Fortaleza -CE. E-mail: romulosoares@ufc.br. Telefone: (85) 98196-8665

2 Pesquisador 1D - CNPq, Doutora em Engenharia de Produção pela Universidade Federal de Santa Catarina. Professora do Departamento de Administração da Universidade Federal do Ceará. Endereço: Avenida da Universidade, 2470 - Benfica - CEP 60020-180 - Fortaleza CE. E-mail: mabreu@ufc.br. Telefone: (85) 3366-7823

3 Mestre em Administração e Controladoria pela Universidade Federal do Ceará -Instituto Federal de Brasília - Campus Brasília - SGAN 610 (610 Norte), Módulo D, E, F e G -Fone: pedro.marino@ifb.edu.br (61) $99607-2756$

4 Doutora em Estatística e Investigação Operacional pela Faculdade de Ciências da Universidade de Lisboa. Professora do Departamento de Administração da Universidade Federal do Ceará. Endereço: Avenida da Universidade, 2470 - Benfica - CEP 60020-180 Fortaleza -CE. E-mail: smdpedro@gmail.com Telefone: (85) 3366-7825. 
Palavras-chave: Teoria Institucional, Evidenciação, Relatório de Sustentabilidade, Responsabilidade Social Corporativa, Partes Interessadas.

\title{
HIERARCHICAL INFLUENCE OF COUNTRY, SECTOR AND COMPANY LEVEL IN THE CORPORATE SOCIAL RESPONSIBILITY DISCLOSURE
}

\begin{abstract}
The study performs a hierarchical evaluation of the influence of the national business system (NBS), industrial sector and financial performance in the disclosure of corporate social responsibility. The assumptions of the institutional theory are used to investigate the influence of the national business system on the evidence of social and environmental practices in companies from the basic materials, oil and gas and utility sectors. The study analyzes 264 observations from companies that have shares traded on the Brazilian stock exchanges (BM \& FBovespa) and Canada (Toronto Stock Exchange). A longitudinal study was carried out, adopting descriptive statistics and econometric estimation with a hierarchical model. The results indicate that the percentage of the variance of the random effect is greater explained by the NBS levels, followed by financial characteristics of the companies. The research reinforces the need for managers to assess the characteristics that shape the national business system by establishing their disclosure strategies.
\end{abstract}

Keywords: Institutional Theory, Disclosure, Sustainability Report, Corporate Social Responsibility, Stakeholders.

\section{INTRODUÇÃO}

A teoria de sistemas de negócios considera que a diferença das práticas empresariais existentes entre os países pode ser explicada a partir do contexto institucional (TEMPEL; WALGENBACH, 2007). Esta teoria defende que as nações estão presas a uma determinada trajetória de desenvolvimento, refletindo diferenças nas configurações institucionais, que influenciam o papel $e$ a estruturação das empresas (BROOKES; BREWSTER; WOOD, 2005). Os estados nacionais são, portanto, a principal unidade de competição política, de legitimidade, definidor e defensor dos direitos de propriedade privada, além de ser a influência predominante sobre as instituições do mercado de trabalho (WHITLEY, 2003).

Campbell (2006) desenvolveu uma série de proposições, estabelecendo as condições institucionais sob as quais as empresas, provavelmente, agirão de forma socialmente responsável. É necessário existir: regulação governamental, auto regulação do setor, monitoramento de ONGs e de outras instituições da sociedade civil. Somado a estes fatores, a atuação responsável é provável de ocorrer em um ambiente institucional normativo, em que as empresas estabeleçam um diálogo institucionalizado com seus stakeholders.

As estruturas institucionais do sistema nacional de negócios (SNN), que envolvem as dimensões político, financeiro, de educação, trabalho e cultural, 
são capazes de influenciar práticas explícitas de responsabilidade social corporativa (RSC) (MATTEN; MOON, 2008). Ioannou e Serafeim (2012) utilizaram o framework proposto por Whitley (1999) e analisaram os impactos dos sistemas nacionais de negócio (SNN) na variação do desempenho social corporativo. $O$ estudo com empresas de 42 países, em um período de 7 anos, confirmou impactos significativos de todos os SNN no desempenho social corporativo.

Dessa forma, é necessário compreender a influência dessas instituições na promoção e difusão de padrões de RSC (TSCHOPP; WELLS; BARNEY, 2012). Outrossim, existem diferenças no SNN de países desenvolvidos e em desenvolvimento que afetam a dinâmica de RSC (ABREU; CUNHA; BARLOW, 2015; JAMALI; MIRSHAK, 2007). Este aspecto havia sido ressaltado por Jones (1999), que indicou a importância do ambiente sociocultural e o nível do desenvolvimento econômico, além de características organizacionais e do setor industrial, como importantes variáveis que influenciam a compreensão da RSC e suas práticas.

Abreu et al. (2015) reconhecem que o contexto institucional não é estático. Existem forças institucionais que influenciam o campo organizacional e as empresas a adotarem práticas de responsabilidade social corporativa. 0 estudo das diferenças abordagens de RSC, entre países desenvolvidos e em desenvolvimento, ganha um novo contorno, na medida em que países em desenvolvimento surgem como novos atores, competindo com os países desenvolvidos por espaço na economia global. Contudo, países em desenvolvimento possuem questões sociais e arranjos institucionais únicos, que necessitam abordagens e práticas de RSC diferentes daquelas adotadas nos países desenvolvidos (IDEMUDIA, 2011; KOLK; LENFANT, 2010; MOON; SHEN, 2010).

Este estudo amplia este debate sobre evidenciação de práticas de RSC, ao examinar a seguinte questão de pesquisa: Em que extensão fatores atribuídos ao sistema nacional de negócios, ao setor industrial e ao desempenho financeiro da empresa influenciam a evidenciação de práticas de responsabilidade social corporativa? Esse cenário pode ser exemplificado pelo caso do Canadá e Brasil, os quais apresentam distintas estruturas institucionais. Por exemplo, no aspecto do desenvolvimento social, entre 2007 e 2014, o Índice de Desenvolvimento Humano (IDH) do Canadá cresceu de 0,895 para 0,913, enquanto, o do Brasil aumentou de 0,721 para 0,755 (UNDP, 2017). Contudo, do ponto de vista econômico, os dois países são praticamente iguais, em relação ao PIB. Em 2015, o Brasil passou para 9a posição e o Canadá para a 10ª entre as maiores economias mundiais.

A contribuição deste estudo ocorre por meio da identificação da influência relativa dos níveis de análise na extensão da evidenciação de RSC, em um país desenvolvido e outro em desenvolvimento. Pesquisas anteriores se concentraram em países desenvolvidos, e em análises isoladas da influência de fatores organizacionais, do setor, do país ou do sistema nacional de negócio (CONCEIÇÃO et al., 2011; GONÇALVES, 2011 ; IOANNOU; SERAFEIM, 2012; FIFKA; 2013; MENG et al., 2014; MICHELON; PILONATO; RICCERI, 2015). Pouco se sabe sobre a influência relativa desses níveis (ORLITZKY et al., 2017). É fundamental, portanto, compreender quais são os principais fatores que afetam a evidenciação, especialmente, aqueles fora dos limites das empresas e fora do 
controle direto dos gestores (TSCHOPP, WELLS; BARNEY, 2012; ORLITZK; LOUCHE; GOND; CHAPPLE, 2017).

Com base no exposto, a próxima sessão apresenta a influência das características do sistema nacional de negócios, do setor industrial e do desempenho financeiro da empresa sobre a evidenciação da responsabilidade social corporativa, em países desenvolvidos e em desenvolvimento. Em seguida, apresenta-se construção das hipóteses da pesquisa e a metodologia adotada. Realizou-se então uma análise longitudinal, em uma amostra contendo 264 observações, no período de 2007 a 2015, divididas em 127 observações de empresas no Brasil e 137 no Canadá, tomando por base dados coletados nos relatórios de empresas listadas na BM\&FBovespa (Brasil) e na Toronto Stock Exchange (Canadá).

A pesquisa adotou a modelagem econométrica de regressão hierárquica, a qual permite lidar com dados que tem diferentes níveis de agregação, através da decomposição dos erros em efeitos aleatórios relacionados aos diversos níveis de análise (NATIS, 2001). Finalmente, são apresentados e discutidos os resultados da pesquisa, os quais reforçam a influência relativa de efeitos multiníveis na evidenciação de responsabilidade social corporativa.

\section{FATORES DETERMINANTES NA EVIDENCIAÇÃO DE RESPONSABILIDADE SOCIAL CORPORATIVA}

Responsabilidade social corporativa pode ser definida como a situação na qual as empresas vão além do simples cumprimento de obrigações legais e se engajam em ações que promovam bem estar social, indo além dos interesses da empresa (MCWILLIAMS, SIEGE; WRIGHT, 2006). A evidenciação das práticas de responsabilidade social corporativa é considerada um pré-requisito para a manutenção de uma imagem positiva junto ao mercado (CONCEIÇÃO; DOURADO; BAQUEIRO; FREIRE; BRITO, 2011). Através da evidenciação, as empresas fornecem informações para diferentes stakeholders a respeito de suas práticas sociais e ambientais (GOLOB; BARTLETT, 2007). A evidenciação é, portanto, uma ferramenta de gestão e comunicação, endereçada aos stakeholders. Permite também, que a empresa avalie seu desempenho social corporativo e defina suas estratégias e metas.

Tang e Li (2009) argumentam que a evidenciação é uma atividade padrão, através da qual as empresas divulgam suas práticas relacionadas com a proteção, as condições de trabalho, e ao seu desempenho financeiro. As empresas passaram a desenvolver a gestão e os mecanismos organizacionais para a evidenciação e controle das políticas e práticas sociais e ambientais (CARROLL, 2008). Os relatórios de sustentabilidade são, portanto, uma ferramenta chave de evidenciação aos stakeholders, sobre as atividades socialmente responsáveis das empresas (GOLOB; BARTLETT, 2007).

Fifka (2013) afirma que as pesquisas analisam, predominantemente, fatores organizacionais que influenciam a evidenciação. Esses fatores envolvem, principalmente, o tamanho da empresa, o setor e indicadores de desempenho 
financeiro. No entanto, existem fatores externos à empresa, que também influenciam na evidenciação. Dentre estes fatores, destacam-se aqueles relacionados às características dos países, tais como o ambiente político e socioeconômico. Campbell (2006) atribui às instituições nacionais, como prováveis responsáveis pelas diferenças transacionais nas atitudes gerenciais relativas à RSC. Pesquisas sugerem a influência (ou não) de variáveis de análise nos níveis macro (e.g. país ou sistema nacional de negócios), meso (e.g. setor de atuação) e micro (e.g. fatores financeiros) na extensão da evidenciação de RSC. No entanto, Orlitzky et al. (2017) enfatizam a necessidade de avançar empiricamente na demonstração dos pesos relativos de cada um desses níveis.

\subsection{Influência do ambiente institucional na evidenciação de RSC em países desenvolvidos e em desenvolvimento}

O ambiente institucional de um país tem um forte impacto nas práticas de responsabilidade social corporativa. Segundo Aguilera e Jackson (2003), as instituições de um país moldam os processos sociais e políticos, de como os interesses dos stakeholders são definidos (ou socialmente construídos) em relação à empresa. Tschopp et al. (2012) argumentam que as instituições podem, por exemplo, promover ou influenciar a difusão de padrões de relatórios de RSC, através de esforços para: comunicar os benefícios da utilização ou emissão dos relatórios; ajudar as empresas na elaboração dos relatórios; desenvolver, harmonizar, ou convergir diretrizes; e no desenvolvimento de mercados e pressões destinadas a aumentar a confiança nos relatórios de sustentabilidade.

Matten e Moon (2008) assumem a necessidade de algumas pré-requisitos para uma atuação socialmente responsável. Para a existência da RSC, é necessário: um mercado em que as empresas tenham liberdade para decidir suas respostas estratégicas; a existência de instituições governamentais e legais que garantam, definam e administrem o mercado; e ajam em nome da sociedade para corrigir disfunções. As instituições não podem ser manipuladas por agentes do mercado. Requer a existência de uma sociedade civil que institucionalize e articule valores e preferências sociais, nas quais o governo e o mercado busquem responder.

Campbell (2006) atribui às especificidades das instituições como prováveis responsáveis pelas diferenças transacionais nas atitudes gerenciais relativas à RSC. Similarmente, diversos estudos indicam a influência do contexto nacional dos países na adoção de práticas de RSC (JONES, 1999; JAMALI; MIRSHAK, 2007; MATTEN; MOON, 2008; GRECCO et al., 2013). Delmas (2002) oferece um quadro teórico para analisar a variação nas taxas de adoção da norma ISO 14001 entre Estados Unidos e Europa. A pesquisa mostrou que o ambiente institucional norteamericano parece agir como um fator que desencoraja a adoção da ISO 14001. Empresas americanas são temerosas do processo de certificação, que torna público informações sobre seu desempenho. Por outro lado, na Europa, os governos têm encorajado a adoção de diretrizes de gestão ambiental, através do estabelecimento de sistemas de certificação confiáveis, e provendo assistência técnica aos potenciais adotantes. 
Ao estudar o contexto chinês, Tang e Li (2009) explicam que a conceituação, práticas e comunicação de RSC são determinadas pela complicada interação entre as empresas, governos, ONGs e outros stakeholders da sociedade chinesa, e as pressões institucionais das comunidades local e global. Yang, Craig e Farley (2015) reforçam a visão popular de que a evidenciação de informação de RSC está sujeita ao contexto social e político do país em que a empresa opera. Estes trabalhos enfatizaram a importância do governo chinês como promotor da transparência das empresas. Na China, o aumento na evidenciação de RSC está relacionado, também, às mudanças na sua economia. Antes considerado como um custo adicional, a ausência de evidenciação passou a ser uma barreira para o mercado internacional. Assim, na medida em que empresas chinesas entravam nesse mercado, o governo chinês percebeu que era necessário promover a evidenciação.

Resultados encontrados por Grecco et al. (2013) corroboram a hipótese de que existe diferença nas práticas de evidenciação entre empresas brasileiras e espanholas. As atividades corporativas e as práticas de evidenciação são motivadas por expectativas e pressões sociais específicas de cada contexto, conforme os pressupostos da teoria institucional. Bewley e Li (2000) examinam fatores associados com a evidenciação ambiental nos relatórios anvais das empresas canadenses de manufatura.

Empresas com mais cobertura midiática da sua exposição ambiental, maior propensão à polvição e mais exposição política são mais propensas a divulgarem informações ambientais. Abreu, Cunha e Barlow (2015) argumentam que os países desenvolvidos por terem um claro conjunto de parâmetros e orientações relacionados à RSC limitam as respostas das empresas. Por outro lado, nos países em desenvolvimento, os limites são mais turvos e permitem que as empresas experimentem novas formulações e definições de sustentabilidade corporativa.

\subsection{Influência do setor industrial e de fatores associados ao desempenho financeiro da empresa na evidenciação de RSC}

Diversas pesquisas utilizam alguma variável relacionada ao setor industrial para explicar o comportamento socialmente responsável das empresas (GONÇALVES, 2011; SILVA et al., 2013; GÓIS et al. 2015; MICHELON, PILONATO; RICCERI, 2015). Os resultados encontrados por Silva et al. (2013) identificam que às empresas pertencentes a setores ambientalmente sensíveis tendem a divulgar mais informações de caráter ambiental. No entanto, pesquisas mais recentes como de Góis et al. (2015) e Michelon et al. (2015) apontam que a variável que associa a empresa a setores ambiental e socialmente sensíveis não é significante em relação a evidenciação.

Estudos realizados por Ho e Taylor (2007), Grecco et al. (2013), Yang et al. (2015) e Muttakin, Khan e Subramaniam (2015) afirmam que quanto maior for a empresa, mais elevado será seu nível de evidenciação. Uma das justificativas para o tamanho da empresa ser determinante para o aumento de informações de RSC é o fato de empresas maiores terem maior exposição na sociedade e menor custo adicional para o aumento de divulgação de informação 
(GONÇALVES, 2011 ). Segundo Góis, de Luca e Vasconcelos (2015), as empresas maiores conseguem produzir informações de melhor qualidade, por serem mais estruturadas e conseguirem captar melhores profissionais. Hou e Reber (2011) encontram relação entre o tamanho da empresa e iniciativas de divulgação de informações de RSC nas maiores empresas de mídia americanas.

Além disso, Jain e Mishra (2011) acham uma relação entre o tamanho da empresa, medido pelo número de empregados, e o volume de vendas, e a avaliação da RSC de empresas indianas. Chauhan e Amit (2014) encontram relação positiva entre o tamanho da empresa e as despesas com RSC. Cordeiro e Tewari (2015) encontram que o tamanho da empresa influencia na reação dos investidores à evidenciação de RSC. No entanto, contrariando a visão tradicional, Parsa e Kouhy (2008) encontram que as pequenas e médias empresas, listadas no Alternative Investment Market na Inglaterra, divulgam informações sociais da mesma forma que as empresas grandes, apesar das restrições financeiras.

Margolis e Walsh (2003) criticam o fato de as pesquisas estarem mais voltadas para investigar como as práticas de RSC afetam o desempenho financeiro das empresas. Para eles é necessário explorar mais a relação oposta, isto é, como as práticas de RSC são influenciadas, tanto pelo desempenho financeiro, como por outras características da empresa. A resposta dada por uma empresa aos impactos sociais e ambientais atribuídos a ela, devem ser explicados não apenas pelo fato dessa reposta trazer vantagens competitivas, mas também depende da sua capacidade de responder a essas questões.

Margolis, Elfenbein e Walsh (2007) defendem que para os estudiosos do campo da RSC, mostrar que uma conduta socialmente responsável estaria associada positivamente com o desempenho financeiro, seria uma forma de legitimar o desempenho social corporativo em termos econômicos. Ruf et al. (2001) frisa que empresas com melhor desempenho financeiro, têm um maior custo de oportunidade, uma vez que um volume maior de recursos pode ser associado pelos stakeholders a uma maior chance de tomadas de decisão oportunistas. Para combater esse comportamento, as empresas buscam adotar mais práticas socialmente responsáveis, com intuito, além de reduzir seu nível de recursos disponíveis, também trabalham sua reputação entre os stakeholders.

Simpson e Kohers (2002), no entanto, levantam a hipótese de que os gestores, ao se depararem com um forte desempenho financeiro, preferem reduzir os investimentos com práticas socialmente responsáveis, a fim de tentar maximizar os lucros de curto prazo, os quais refletem de modo mais imediato no preço das ações. Além disso, Simpson e Kohers (2002), também destacam que gestores, ao se depararem com um desempenho financeiro abaixo do esperado, podem optar por investir em programas sociais, a fim de desviar do aspecto financeiro.

O endividamento é uma outra característica corporativa que se considera poder afetar a evidenciação das práticas de RSC. Segundo Artiach et al. (2010), o nível de débito na estrutura de capital de uma companhia revela uma medida do grau de importância de seus stakeholders financeiros. Os fornecedores de crédito terão mais poder conforme mais uma empresa dependa do financiamento por dívida (ROBERTS, 1992). A medida que o nível de 
endividamento da empresa aumente, aumentará também a influência de seus credores (ARTIACH et al., 2010). Além disso, firmas com menores níveis de endividamento terão maior flexibilidade para financiar suas práticas sociais e ambientais (ZIEGLER; SCHRÖDER, 2010; LOURENÇO; BRANCO, 2013).

\subsection{Construção das hipóteses da pesquisa}

No que tange ao SNN, loannou e Serafeim (2012) argumentam que sua influência sobre práticas de RSC se dá por meio de aspectos regulatórios, que acabam homogeneizando a forma de atuação das empresas. Essa ideia é complementada por Whitley (2003), ao defender que o SNN está relacionado à coerência do ambiente institucional e ajuda a definir componentes estratégicos das empresas. Por outro lado, Orlitzky et al. (2017) parte da ideia de que devido ao fato das forças ligadas ao SNN não atuarem de modo necessariamente homogêneo no que tange à organização interna das empresas, isso reduz a importância do ambiente institucional para a explicação de práticas de RSC adotadas pelas empresas, quando são levadas em consideração as características da firma. Isto é, há uma predominância dos fatores organizacionais na determinação das formas como as empresas adotam tais práticas.

Para confirmar sua hipótese, Orlitzky et al. (2017) avalia a influência de variáveis associadas ao SNN, ao setor e à firma, para a explicação das práticas de RSC de uma amostra com 2.060 empresas, em um painel balanceado de cinco anos (2003 a 2007), em 21 países, sendo 19 deles membros da União Europeia, além dos Estados Unidos e da Coreia do Sul. Os autores mostram que, de modo geral, as variáveis no nível da firma são os principais determinantes para a extensão de RSC das empresas.

Divergente do que foi proposto por Orlitzky et al. (2017), alguns estudos mostram que quando dois países demonstram grandes diferenças no aspecto institucional, essas divergências acabam tendo um maior peso para moldar as práticas organizacionais internas da empresa do que as próprias características das empresas. Salomon e Wu (2012), em linha com esse raciocínio, afirmam que empresas multinacionais, ao operarem fora de seu país de origem, tendem a imitar as práticas adotadas por firmas locais, com 0 intuito de mitigar desvantagens e permanecerem competitivas.

Com respeito à RSC, Yang e Rivers (2009) mostram que a medida em que há uma maior divergência entre o ambiente institucional do país sede de uma empresa e do país em que a subsidiária se localiza, mais difícil é para que as práticas de RSC comumente adotadas na sede sejam replicadas. As empresas então, acabam adotando práticas de RSC semelhantes àquelas adotadas pelas empresas locais. Nesse sentido, percebe-se que, ao comparar empresas de países com um SNN distinto, as estratégias adotadas por estas, podem ser melhor explicadas pelas diferenças existentes no SNN, em detrimento das características das firmas.

Karam e Jamali (2015) observa, com base nessa perspectiva, que há um distanciamento entre os SNN de países desenvolvidos e em desenvolvimento que contribuem de modo significativo para as práticas de RSC. Em países 
desenvolvidos, as práticas de RSC, devem buscar atender, prioritariamente, aspectos econômicos, uma vez que esta é a razão de existência das empresas, seguido de aspectos éticos, legais e em último lugar, aspectos filantrópicos. Para países em desenvolvimento, assim como nos países desenvolvidos, o aspecto econômico da RSC vem em primeiro lugar. No entanto, de modo divergente, o aspecto filantrópico é mais importante do que aspecto legal e o ético. Isso se deve ao fato de que nesses países há uma maior necessidade de filantropia, fruto dos níveis de pobreza, desemprego e outras questões que se fazem mais presentes (JAMALI, 2014).

Com base no exposto, foram estabelecidas as seguintes hipóteses para avaliar a capacidade explicativa de variáveis ligadas ao SNN, ao setor industrial e à firma no tocante a evidenciação de práticas de RSC.

$H_{1}$ : A maior parte da variabilidade na evidenciação de RSC é explicada pelo sistema nacional de negócios do país.

$\mathrm{H}_{2}$ : A menor parte da variabilidade na evidenciação de RSC é explicada pelo setor industrial e desempenho financeiro das empresas.

\section{METODOLOGIA}

\subsection{Caracterização da Pesquisa e Definição da Amostra}

Esta pesquisa caracteriza-se como descritiva (SAMPIERI, COLLADO; LUCIO, 2013), adotando o enfoque quantitativo, na coleta e análise de dados, por meio do uso de modelos hierárquicos para estabelecer os padrões de comportamento das variáveis estudadas e responder as hipóteses formuladas. Foram selecionadas empresas que integram o ranking das "2000 maiores empresas da Forbes", no ano de 2008 (com dados referentes ao ano de 2007). Foram escolhidas para análise as empresas pertencentes aos setores de materiais básicos, de petróleo e gás e de utilidade pública. As empresas que fazem parte desses setores foram escolhidas por serem identificadas como ambientalmente mais sensíveis (GONÇALVES, 2011; MICHELON, PILONATO; RICCERI, 2015).

Por fim, foram selecionadas somente as empresas de capital aberto, com ações negociadas nas bolsas de valores do Brasil (BM\&FBovespa) e do Canadá (Toronto Stock Exchange). Em seguida, foram coletados nos sites institucionais das empresas e no banco de dados da GRI, os relatórios de sustentabilidade relativos ao período de 2007 a 2014. A amostra foi formada por 33 empresas. No total, obteve-se 264 observações, divididas em 127 observações do Brasil e 137 do Canadá.

\subsection{Estimação do Modelo Hierárquico}

Modelos hierárquicos têm a capacidade de trabalhar com relações de dados em níveis diferentes, conseguindo segregar os efeitos das variâncias dentro e entre os grupos (WOLTMAN et al., 2012). A modelagem hierárquica também é preferível quando se trabalha com dados dessa natureza, uma vez 
que se baseia em menos pressupostos do que outros métodos estatísticos (RAUDENBUSH; BRYK, 2002). O Modelo Hierárquico Linear (MHL) é, geralmente, considerado superior à outras formas de análise para dados com estrutura hierárquica (e.g. ASCA - ANOVA Simultaneous Componente Analysis; e VCA Variance Componente Analysis) porque: permite estruturas complexas de erro e pode, dessa forma, modelar dependências entre níveis de análises; tem maior poder estatístico que os outros métodos; e endereça ao problema de colinearidade entre as empresas e os setores.

Segundo Woltman et al. (2012), um modelo hierárquico é robusto quando as observações não são independentes, quando há dados omissos, quando os grupos amostrais têm tamanho discrepante, ou ainda na presença de heterogeneidade. Natis (2001) argumenta que o MHL é adequado para avaliar dados agrupados em estruturas hierárquicas, caracterizadas por unidades experimentais agrupadas em unidades ainda maiores, e funciona como um modelo de efeitos aleatórios que permite especificar os níveis de hierarquia separadamente, incorporando efeitos aleatórios a cada um desses níveis. Assim, esse modelo permite que cada um dos níveis hierárquicos seja especificado separadamente e, posteriormente, reunidos em um único modelo.

Para que seja possível estudar de modo simultâneo as relações existentes dentro de um grupo hierárquico, bem como a forma como os grupos interagem entre si, é necessário que quatro modelos sejam estimados, uma vez que há três níveis hierárquicos na estrutura dos dados que se pretende trabalhar, conforme apresentado a seguir:

$$
\begin{gathered}
\mathrm{EV}_{\mathrm{i}, \mathrm{t}, \mathrm{p}}=\beta_{0}+\beta_{1} \mathrm{SNN}_{\mathrm{i}, \mathrm{p}, \mathrm{t}}+\beta_{2} \text { Setor }_{\mathrm{i}}+\beta_{3} \text { Empresa }_{\mathrm{t}}+\beta_{4: 9} \text { Ano }+\varepsilon_{\mathrm{i}, \mathrm{t}, \mathrm{p}} \\
\beta_{1}=\gamma_{1,0}+\gamma_{1,1} \text { SistPol }_{\mathrm{p}}+\gamma_{1,2} \text { SistTrab }_{\mathrm{p}}+\gamma_{1,3} \text { SistEduc }_{\mathrm{p}}+\gamma_{1,4} \text { SistFin }_{\mathrm{p}}+\gamma_{1,5} \text { SistCult }_{\mathrm{p}}+\mathrm{U}_{1} \\
\beta_{2}=\gamma_{2,0}+\gamma_{2,1: 2} \text { Setor }_{\mathrm{i}}+\mathrm{U}_{2} \\
\beta_{3}=\gamma_{3,0}+\gamma_{3,1} \mathrm{ROA}_{\mathrm{i}, \mathrm{t}, \mathrm{p}}+\gamma_{3,2} \text { Endividamento }_{\mathrm{i}, \mathrm{t}, \mathrm{p}}+\gamma_{3,3} \text { Tamanho }_{\mathrm{i}, \mathrm{p} p}+\mathrm{U}_{3}
\end{gathered}
$$

EV representa a evidenciação da empresa i, do país $\mathrm{p}$, no ano t. Na análise dos resultados, tal evidenciação foi tratada em sua totalidade (EVT), na dimensão ambiental (EVA) e na dimensão social (EVS). $\beta_{1}, \beta_{2}$ e $\beta_{3}$ representam os efeitos aleatórios, respectivamente, associados ao nível do SNN, do setor e da empresa. Esses efeitos são decompostos com base nas variáveis selecionadas para explicar cada um dos níveis. Os modelos utilizados identificam a porcentagem da variância dos efeitos aleatórios.

Para o nível dos fatores associados ao SNN, são utilizados o Sistema Político, Sistema de Trabalho, Sistema de Educação, Sistema Financeiro e Sistema Cultural. Para o nível do setor, são utilizadas variáveis dummy que representam os setores das empresas da amostra (petróleo e gás, materiais básicos e utilidade pública) e aos fatores associados ao desempenho financeiro das empresas, foram utilizados o ROA, Endividamento e Tamanho, conforme apresentados no Quadro 1.

Para avaliar a extensão da divulgação de informação de RSC foram utilizados os indicadores de desempenho da GRI (2011). Esses indicadores foram 
organizados em duas dimensões (ambiental e social), conforme a metodologia proposta por Fischer e Sawczyn (2013). A dimensão ambiental envolve nove categorias e a dimensão social envolve com quatorze categorias. Em seguida, essas duas dimensões foram somadas para formarem a variável EV, que mede a extensão da evidenciação de práticas ambientais e sociais. O resultado obtido para a dimensão total da evidenciação foi dividido pela pontuação máxima, resultando em um indicador com valor entre 0 e 1 . Estas dimensões, suas categorias e os indicadores GRI que as compõem são apresentadas no Quadro 2.

\section{Quadro 1 - Variáveis independentes utilizadas na pesquisa e fonte de dados}

\begin{tabular}{|c|c|c|c|c|}
\hline $\begin{array}{c}\text { Nível } \\
\text { hierárquico }\end{array}$ & Dimensão & Indicador & Operacionalização & Fonte \\
\hline \multirow{5}{*}{$\begin{array}{l}\text { Sistema } \\
\text { Nacional } \\
\quad \text { de } \\
\text { Negócios } \\
\text { (SNN) }\end{array}$} & $\begin{array}{l}\text { Sistema } \\
\text { Político }\end{array}$ & $\begin{array}{l}\text { Worldwide } \\
\text { Governan } \\
\text { ce } \\
\text { Indicators }\end{array}$ & $\begin{array}{l}\text { Compreendem a percepção sobre seis } \\
\text { dimensões: voz e responsabilização, } \\
\text { estabilidade política, eficácia do } \\
\text { governo, qualidade da regulação, } \\
\text { estado de direito e controle de } \\
\text { corrupção, todos medidos em uma } \\
\text { escala de -2,5 a 2,5. }\end{array}$ & $\begin{array}{l}\text { The } \\
\text { World } \\
\text { Bank }\end{array}$ \\
\hline & $\begin{array}{l}\text { Sistema } \\
\text { Financeiro }\end{array}$ & $\begin{array}{l}\text { Financing } \\
\text { through } \\
\text { local } \\
\text { equity } \\
\text { market }\end{array}$ & $\begin{array}{c}\text { Percepção dos executivos de } \\
\text { empresas sobre a facilidade com que } \\
\text { empresas conseguem captar recursos } \\
\text { por meio da emissão de ações e títulos } \\
\text { de dívida com base numa escala que } \\
\text { varia de } 1 \text { a } 7\end{array}$ & \multirow{3}{*}{$\begin{array}{l}\text { Global } \\
\text { Competi } \\
\text { tiveness } \\
\text { Index } \\
\text { (GCl) do } \\
\text { World } \\
\text { Economi } \\
\text { c Forum } \\
\text { (WEF) }\end{array}$} \\
\hline & $\begin{array}{l}\text { Sistema } \\
\text { de } \\
\text { Educação }\end{array}$ & $\begin{array}{l}\text { Quality of } \\
\text { the } \\
\text { education } \\
\text { system }\end{array}$ & $\begin{array}{c}\text { Percepção dos executivos de } \\
\text { empresas sobre o quanto o sistema } \\
\text { educacional do país atende às } \\
\text { necessidades de uma economia } \\
\text { competitiva com base em uma escala } \\
\text { de } 1 \text { a } 7\end{array}$ & \\
\hline & $\begin{array}{l}\text { Sistema } \\
\text { de } \\
\text { Trabalho }\end{array}$ & $\begin{array}{l}\text { Cooperati } \\
\text { on in } \\
\text { labor- } \\
\text { employer } \\
\text { relations }\end{array}$ & $\begin{array}{c}\text { Percepção dos executivos de } \\
\text { empresas sobre as condições de } \\
\text { trabalho com base em uma escala que } \\
\text { varia de } 1 \text { a } 7\end{array}$ & \\
\hline & $\begin{array}{l}\text { Sistema } \\
\text { Cultural }\end{array}$ & $\begin{array}{l}\text { Dimensões } \\
\text { culturais } \\
\text { de } \\
\text { Hofstede }\end{array}$ & $\begin{array}{l}\text { Quatro dimensões da cultura nacional } \\
\text { propostas por Geert Hofstede (1983): } \\
\text { distância do poder, individualismo, } \\
\text { masculinidade, aversão à incerteza, } \\
\text { mensurados numa escala de } 0 \text { a } 100\end{array}$ & $\begin{array}{c}\text { The } \\
\text { Hofstede } \\
\text { Centre }\end{array}$ \\
\hline Setor & $\begin{array}{c}\text { Setor } \\
\text { Industrial }\end{array}$ & $\begin{array}{l}\text { Setor de } \\
\text { atuação } \\
\text { na Forbes } \\
2000\end{array}$ & $\begin{array}{l}\text { Materiais Básicos } \\
\text { Operações de Petróleo e Gás } \\
\text { Utilidade Pública }\end{array}$ & $\begin{array}{l}\text { Forbes } \\
2000\end{array}$ \\
\hline
\end{tabular}




\begin{tabular}{|c|c|c|c|c|}
\hline \multirow{1}{*}{ Empresa } & ROA & $\begin{array}{c}\text { Rentabilid } \\
\text { ade dos } \\
\text { Ativos }\end{array}$ & $\begin{array}{c}\text { Razão entre o Lucro Antes dos Juros e } \\
\text { IR e o Ativo Total }\end{array}$ & \\
\cline { 2 - 4 } & $\begin{array}{c}\text { Endividam } \\
\text { ento } \\
\text { ão de } \\
\text { Capitais } \\
\text { de } \\
\text { Terceiros }\end{array}$ & $\begin{array}{r}\text { Razão entre a soma do Passivo } \\
\text { Circulante e Não Circulante com o } \\
\text { Ativo Total }\end{array}$ & \multirow{2}{*}{$\begin{array}{c}\text { Relatório } \\
\text { s Anvais }\end{array}$} \\
\cline { 2 - 4 } & Tamanho & $\begin{array}{c}\text { Logaritmo } \\
\text { natural do } \\
\text { Ativo Total }\end{array}$ & $\begin{array}{c}\text { Logaritmo natural do Ativo Total das } \\
\text { empresas. O Ativo Total das empresas } \\
\text { canadenses foi convertido por meio da } \\
\text { cotação vigente entre o dólar } \\
\text { canadense e o real no último dia do } \\
\text { ano de referência dos dados }\end{array}$ & \\
\hline
\end{tabular}

Fonte: elaborado pelos autores

\section{Quadro 2 - Indicadores das dimensões ambiental e social usados para compor a variável dependente Evidenciação (EV)}

\begin{tabular}{|c|c|}
\hline Dimensão ambiental (pontuação máxima 54). & Indicador GRI \\
\hline Percentagem de materiais utilizados que são provenientes de reciclagem. & EN2 \\
\hline $\begin{array}{l}\text { Consumo direto/indireto de energia, discriminado por fonte de energia } \\
\text { primária. }\end{array}$ & EN3/EN4 \\
\hline Consumo total e Descarte total de água, por fonte/destino. & EN8/EN21 \\
\hline $\begin{array}{l}\text { Descrição dos impactos significativos de atividades, produtos e serviços } \\
\text { sobre a biodiversidade das áreas protegidas e sobre as áreas de alto } \\
\text { índice de biodiversidade fora das áreas protegidas. }\end{array}$ & EN11/EN12 \\
\hline $\begin{array}{l}\text { Emissões totais diretas e indiretas de gases com efeito de estufa (Emissão } \\
\text { de substâncias destruidoras da camada de ozônio, NOx, SOx e outras } \\
\text { emissões atmosféricas significativas), por peso. }\end{array}$ & $\begin{array}{l}\text { EN16/EN17/EN } \\
19 / \text { EN20 }\end{array}$ \\
\hline Quantidade total de resíduos, por tipo e método de eliminação. & EN22 \\
\hline $\begin{array}{l}\text { Iniciativas para mitigar os impactos ambientais de produtos e serviços e } \\
\text { grau de redução do impacto. }\end{array}$ & EN26 \\
\hline $\begin{array}{l}\text { Percentagem recuperada de produtos vendidos e respectivas } \\
\text { embalagens, por categoria. }\end{array}$ & EN27 \\
\hline $\begin{array}{l}\text { Implicações financeiras e outros riscos e oportunidades para as atividades } \\
\text { da organização, devido às alterações climáticas. }\end{array}$ & EC2 \\
\hline Dimensão social (pontuação máxima 84). & ador GRI \\
\hline $\begin{array}{l}\text { Discriminação da mão de obra total, por tipo de emprego, por contrato } \\
\text { de trabalho e por região e taxa de rotatividade, por faixa etária, gênero e } \\
\text { região. }\end{array}$ & LAl/LA2 \\
\hline $\begin{array}{l}\text { Taxa de lesões, doenças profissionais, dias perdidos, absentismo e óbitos } \\
\text { relacionados com o trabalho, por região. }\end{array}$ & LA7 \\
\hline $\begin{array}{l}\text { Média de horas por formação, por ano, por trabalhador, discriminadas } \\
\text { por categoria de funções. }\end{array}$ & LA10 \\
\hline $\begin{array}{l}\text { Composição dos órgãos sociais da empresa e relação dos trabalhadores } \\
\text { por categoria, de acordo com o gênero, a faixa etária, as minorias e } \\
\text { outros indicadores de diversidade. }\end{array}$ & LA13 \\
\hline $\begin{array}{l}\text { Razão entre o salário base de homens e mulheres, por categoria e } \\
\text { funções. }\end{array}$ & LA 14 \\
\hline $\begin{array}{l}\text { Cobertura das obrigações referentes ao plano de benefícios definidos } \\
\text { pela organização. }\end{array}$ & EC3 \\
\hline de casos de discriminação e ações tomadas. & HR4 \\
\hline $\begin{array}{l}\text { Casos em que exista um risco significativo de ocorrência de trabalho } \\
\text { infantil, e medidas que contribuam para sua eliminação. }\end{array}$ & HR6 \\
\hline Casos em que exista um risco significativo de ocorrência de trabalho & HR7 \\
\hline
\end{tabular}


forçado ou escravo, e medidas que contribuam para sua eliminação.

Porcentagem e número total de unidades de negócio alvo de análise de

risco à corrupção e medidas tomadas em resposta a casos de corrupção.

$\mathrm{SO} 2 / \mathrm{SO} 4$

Políticas, práticas e proporção de custos com fornecedores locais, em

unidades operacionais importantes.

EC6

Desenvolvimento e impacto dos investimentos em infraestruturas e serviços

que visam essencialmente o benefício público através de envolvimento

EC8

comercial, em gêneros ou pro bono.

Estágios do ciclo de vida dos produtos e serviços em que os impactos de

saúde e segurança são avaliados com o objetivo de efetuar melhorias,

bem como a porcentagem das principais categorias de produtos e

serviços sujeitas a tais procedimentos.

Tipo de informação sobre produtos e serviços exigida por regulamentos, e

a percentagem de produtos e serviços significativos sujeitos a tais

requisitos.

Fonte: Fischer e Sawczyn (2013).

Dimensão Total (pontuação máxima 138)

Conforme estabelecido por Fischer e Sawczyn (2013), cada categoria foi pontuada de 0 a 6 , seguindo a seguinte metodologia: 0 quando não é divulgada informação; 1 quando a informação de desempenho é apresentada em termos absolutos ou relativos. Soma-se mais 1 ponto quando, além da informação em termos absolutos ou relativos, ela também é dada: em relação a empresas semelhantes/rivais ou setor; em comparação com períodos passados; em relação às metas estipuladas; de forma normalizada ou de forma desagregada. Naquelas categorias que apresentam mais de um indicador (ex.: Categoria 2 formada pelo indicador EN3 e EN4), cada um foi avaliado separadamente e depois considerada a maior pontuação entre eles.

Para testar a confiabilidade das variáveis compostas por mais de um item, como as variáveis de extensão de evidenciação de RSC, foi utilizado o teste de alfa de Cronbach (1951). Este teste calcula a aderência dos itens que compõem uma escala através das variâncias dos itens e dos seus totais (MAROCO, GARCIA-MARQUES, 2006).

Dessa forma, o modelo hierárquico proposto se endereça a decompor o erro, atribuindo uma estrutura complexa relacionada aos níveis em que os dados estão agrupados, ou seja, relacionados ao país, ao setor e à empresa. 0 modelo hierárquico de dados foi estimado através do método da máxima verossimilhança. Para a realização dos testes foram utilizados o programa estatístico STATA® versão 13.

\section{RESULTADOS}

\subsection{Análise descritiva das variáveis relacionadas à divulgação de informação}

Com base nos dados da pesquisa, o ano de maior adesão à evidenciação de RSC foi 2011, em que todas as empresas da amostra divulgaram seus relatórios de sustentabilidade. Conforme a Tabela 1, as empresas brasileiras divulgaram, proporcionalmente, mais relatórios de sustentabilidade do que as empresas canadenses. Somente em dois anos todas 
as empresas canadenses da amostra divulgaram relatórios (2011 e 2012), enquanto no Brasil, em cinco anos (2008, 2009, 2010, 2011 e 2014), todas as empresas da amostra divulgaram seus relatórios. Ressalta-se que a quantidade menor de relatórios em 2015 deve-se ao fato de que, quando a coleta dos dados fora realizada, muitas empresas ainda não haviam divulgado seus relatórios de sustentabilidade para aquele ano.

Quanto ao setor, observa-se que por cinco anos consecutivos (2010 a 2014) todas as empresas de operação de petróleo e gás da amostra divulgaram seus relatórios de sustentabilidade. O setor de materiais básicos, apesar de ser aquele com maior quantidade de empresas, devido, principalmente à relevância do setor de mineração e siderurgia para Brasil e Canadá, apresenta um comportamento mais instável quanto à divulgação dos relatórios por parte das empresas.

Tabela 1 - Frequência de divulgação dos relatórios de sustentabilidade por país e setor, 2007-2015

\begin{tabular}{lcccccccccc}
\hline País/setor & $\mathbf{2 0 0 7}$ & $\mathbf{2 0 0 8}$ & $\mathbf{2 0 0 9}$ & $\mathbf{2 0 1 0}$ & $\mathbf{2 0 1 1}$ & $\mathbf{2 0 1 2}$ & $\mathbf{2 0 1 3}$ & $\mathbf{2 0 1 4}$ & $\mathbf{2 0 1 5}$ & Total \\
\hline Brasil & 14 & 15 & 15 & 15 & 15 & 14 & 14 & 15 & 10 & $\mathbf{1 2 7}$ \\
Canadá & 14 & 14 & 16 & 16 & 18 & 18 & 16 & 16 & 9 & $\mathbf{1 3 7}$ \\
\hline Materiais Básicos & 13 & 13 & 14 & 13 & 15 & 14 & 13 & 15 & 9 & $\mathbf{1 1 9}$ \\
Operação de P\&G & 7 & 8 & 8 & 9 & 9 & 9 & 9 & 9 & 7 & $\mathbf{7 5}$ \\
Utilidade Pública & 8 & 8 & 9 & 9 & 9 & 9 & 8 & 7 & 3 & $\mathbf{7 0}$ \\
\hline Total & $\mathbf{2 8}$ & $\mathbf{2 9}$ & $\mathbf{3 1}$ & $\mathbf{3 1}$ & $\mathbf{3 3}$ & $\mathbf{3 2}$ & $\mathbf{3 0}$ & $\mathbf{3 1}$ & $\mathbf{1 9}$ & $\mathbf{2 6 4}$ \\
\hline \multicolumn{7}{c}{ Fonte: dados da pesquisa. }
\end{tabular}

Após a análise da composição da amostra, avalia-se a evidenciação de RSC pelas empresas, segregando-as por país e setor. Na Tabela 2 é apresentada a estatística descritiva da variável EVA (evidenciação da dimensão ambiental). A extensão máxima desta dimensão no Brasil foi $54 \%$ e no Canadá foi $44 \%$. A média para o período foi de 0,24 para o Brasil, com desvio padrão de 0,13, e de 0,23 para o Canadá, com desvio padrão de 0,11.

No período a divulgação média do Brasil foi superior a canadense em praticamente todos os anos, com exceção de 2009. No entanto, conforme observado na Tabela 2 as médias dos países foram muito próximas e o Brasil possui desvio padrão superior ao canadense, sugerindo uma maior dispersão na divulgação dentro da amostra.

Tabela 2 - Estatística descritiva da dimensão ambiental da evidenciação, 2007-2015

\begin{tabular}{|c|c|c|c|c|c|c|c|c|c|c|c|}
\hline País & & $\begin{array}{c}200 \\
7\end{array}$ & $\begin{array}{c}200 \\
8\end{array}$ & $\begin{array}{c}200 \\
9\end{array}$ & $\begin{array}{c}201 \\
0\end{array}$ & $\begin{array}{c}201 \\
1\end{array}$ & $\begin{array}{c}201 \\
2\end{array}$ & $\begin{array}{c}201 \\
3\end{array}$ & $\begin{array}{c}201 \\
4\end{array}$ & 2015 & Total* \\
\hline \multirow[t]{4}{*}{ Brasil } & Mínimo & 0,00 & 0,00 & 0,00 & 0,01 & 0,01 & 0,03 & 0,06 & 0,04 & 0,10 & 0,00 \\
\hline & Máximo & 0,34 & 0,36 & 0,42 & 0,43 & 0,52 & 0,53 & 0,53 & 0,42 & 0,30 & 0,53 \\
\hline & Média & 0,16 & 0,18 & 0,16 & 0,22 & 0,23 & 0,25 & 0,24 & 0,23 & 0,22 & 0,21 \\
\hline & Desvio & 0,12 & 0,13 & 0,14 & 0,13 & 0,14 & 0,15 & 0,14 & 0,12 & 0,07 & 0,13 \\
\hline \multirow[t]{4}{*}{$\begin{array}{c}\text { Cana } \\
\text { dá }\end{array}$} & Mínimo & 0,00 & 0,00 & 0,00 & 0,00 & 0,07 & 0,07 & 0,07 & 0,00 & 0,06 & 0,00 \\
\hline & Máximo & 0,48 & 0,48 & 0,43 & 0,43 & 0,43 & 0,43 & 0,43 & 0,40 & 0,34 & 0,48 \\
\hline & Média & 0,19 & 0,17 & 0,19 & 0,19 & 0,23 & 0,24 & 0,26 & 0,24 & 0,20 & 0,21 \\
\hline & Desvio & 0,13 & 0,14 & 0,11 & 0,13 & 0,10 & 0,10 & 0,10 & 0,12 & 0,10 & 0,12 \\
\hline
\end{tabular}

Fonte: dados da pesquisa.

*Considerando todos os dados da amostra. 
Na Figura 1 observa-se a extensão da evidenciação média da dimensão ambiental por setor no Brasil e Canadá. Entre 2007 e 2015, em média a divulgação do Brasil no setor de Materiais Básicos foi $25 \%$, enquanto no Canadá foi $18 \%$. No setor de Operação de Petróleo e Gás a evidenciação do Canadá foi superior ao brasileiro em 12\%. O setor de Utilidade Pública teve a maior evidenciação na dimensão ambiental no período. Neste setor, a evidenciação média do Canadá foi superior em $4 \%$ em comparação ao Brasil.

\section{Figura 1 - Evidenciação média da dimensão ambiental por setor, Brasil e Canadá, 2007-2015}

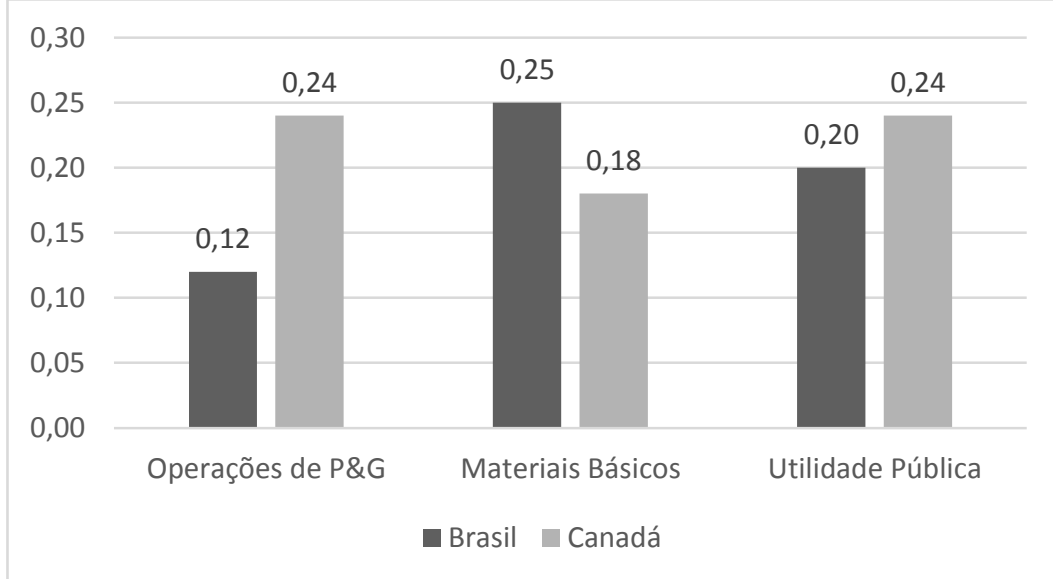

Fonte: Dados da pesquisa.

Na Tabela 3 é apresentada a estatística descritiva da variável da dimensão social da divulgação. A extensão máxima desta dimensão no Brasil foi $44 \%$ e no Canadá foi $36 \%$. A média para o período foi de $19 \%$ para o Brasil, com desvio padrão de 0,12, e 15\% para o Canadá, com desvio padrão de 0,09. No período a divulgação média do Brasil foi superior à canadense em todos os anos. Porém, da mesma forma que a dimensão ambiental as médias dos países foram muito próximas, com o desvio padrão brasileiro sendo superior ao canadense, indicando uma maior dispersão na divulgação.

A extensão da divulgação média da dimensão social por setor no Brasil e Canadá é apresentada na Figura 2. Os resultados dessa dimensão repetiram os da dimensão ambiental. No setor de Materiais Básicos a divulgação média do Brasil foi superior a canadense, neste caso em $8 \%$. No setor de Operação de Petróleo e Gás a evidenciação do Canadá foi superior ao brasileiro em $7 \%$ e no setor de Utilidade Pública, que também teve a maior divulgação de informação na dimensão social, a divulgação média do Canadá foi superior em $2 \%$ à brasileira.

Tabela 3 - Estatística descritiva da dimensão social da evidenciação, 2007-2015

\begin{tabular}{cc|ccccccccc|c}
\hline País & & $\mathbf{2 0 0 7}$ & $\mathbf{2 0 0 8}$ & $\mathbf{2 0 0 9}$ & $\mathbf{2 0 1 0}$ & $\mathbf{2 0 1 1}$ & $\mathbf{2 0 1 2}$ & $\mathbf{2 0 1 3}$ & $\mathbf{2 0 1}$ & $\mathbf{2 0 1 5}$ & Total* \\
\hline \multirow{2}{*}{ Brasil } & Mínimo & 0,00 & 0,00 & 0,00 & 0,01 & 0,01 & 0,01 & 0,00 & 0,02 & 0,08 & 0,00 \\
& Máximo & 0,34 & 0,38 & 0,41 & 0,43 & 0,43 & 0,42 & 0,39 & 0,33 & 0,23 & 0,43 \\
& Média & 0,15 & 0,17 & 0,17 & 0,22 & 0,22 & 0,22 & 0,18 & 0,18 & 0,16 & 0,19 \\
& Desvio & 0,11 & 0,11 & 0,13 & 0,13 & 0,13 & 0,13 & 0,14 & 0,11 & 0,05 & 0,12 \\
\hline
\end{tabular}




\begin{tabular}{cc|ccccccccc|c}
\hline $\begin{array}{c}\text { Canad } \\
\text { á }\end{array}$ & Mínimo & 0,00 & 0,00 & 0,00 & 0,00 & 0,03 & 0,03 & 0,05 & 0,00 & 0,00 & 0,00 \\
& Máximo & 0,36 & 0,36 & 0,35 & 0,35 & 0,34 & 0,36 & 0,36 & 0,33 & 0,27 & 0,36 \\
& Média & 0,12 & 0,11 & 0,14 & 0,14 & 0,16 & 0,16 & 0,18 & 0,15 & 0,13 & 0,14 \\
& Desvio & 0,11 & 0,12 & 0,10 & 0,09 & 0,08 & 0,09 & 0,08 & 0,09 & 0,08 & 0,09 \\
\hline
\end{tabular}

Fonte: dados da pesquisa.

Nota: *Considerando todos os dados da amostra.

Figura 2 - Evidenciação média da dimensão social por setor, Brasil e Canadá, 2007-2015

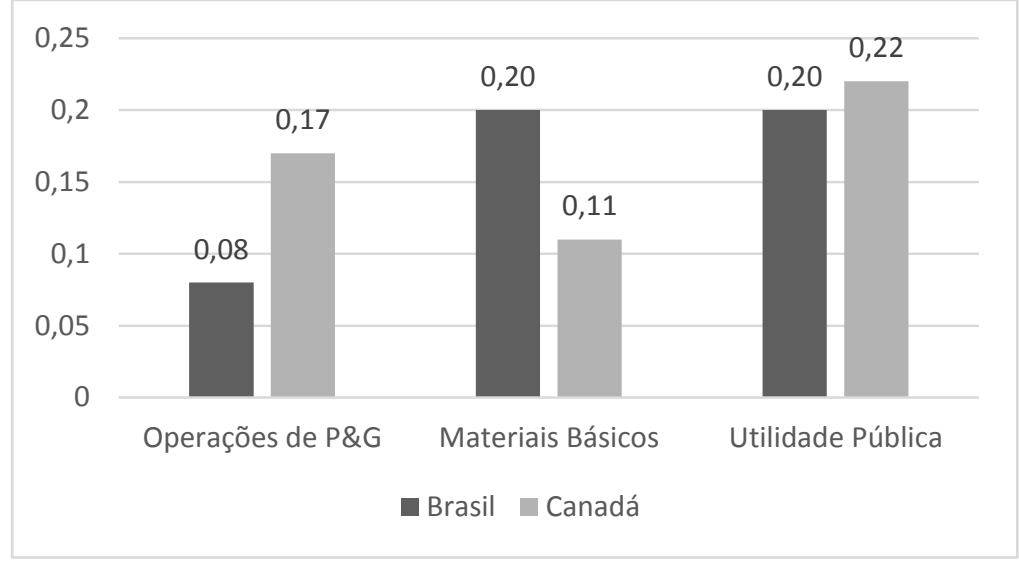

Fonte: Dados da pesquisa.

Na Tabela 4 é apresentada a estatística descritiva da evidenciação quando considerado em sua dimensão total. A extensão máxima desta dimensão no Brasil foi $46 \%$ e no Canadá foi $42 \%$. A média para o período foi de $20 \%$ para o Brasil, com desvio padrão de 12\%, e 18\% para o Canadá, com desvio padrão de $0,10 \%$. Por ser resultado da soma das dimensões ambiental e social os resultados dessa dimensão foram similares aos anteriores, conforme observado na Figura 3.

Tabela 4 - Estatística descritiva da evidenciação total, 2007-2015

\begin{tabular}{|c|c|c|c|c|c|c|c|c|c|c|c|}
\hline País & & 2007 & 2008 & 2009 & 2010 & 2011 & 2012 & 2013 & $\begin{array}{c}201 \\
4\end{array}$ & 2015 & Total* \\
\hline \multirow[t]{4}{*}{ Brasil } & Mínimo & 0,00 & 0,00 & 0,00 & 0,01 & 0,03 & 0,03 & 0,03 & 0,04 & 0,09 & 0,00 \\
\hline & Máximo & 0,30 & 0,35 & 0,41 & 0,42 & 0,46 & 0,46 & 0,43 & 0,34 & 0,26 & 0,46 \\
\hline & Média & 0,16 & 0,17 & 0,16 & 0,22 & 0,23 & 0,23 & 0,21 & 0,20 & 0,19 & 0,20 \\
\hline & Desvio & 0,11 & 0,11 & 0,13 & 0,13 & 0,13 & 0,14 & 0,13 & 0,11 & 0,06 & 0,12 \\
\hline \multirow{4}{*}{$\begin{array}{c}\text { Canad } \\
\text { á }\end{array}$} & Mínimo & 000 & م00 & 00 & חم & 05 & $\cap 05$ & אחم & ח ח & 0 & חمח \\
\hline & Máximo & 0,42 & 0,42 & 0,39 & 0,39 & 0,39 & 0,40 & 0,40 & 0,37 & 0,31 & 0,42 \\
\hline & Média & 0,15 & 0,14 & 0,17 & 0,16 & 0,19 & 0,20 & 0,22 & 0,19 & 0,16 & 0,18 \\
\hline & Desvio & 0,12 & 0,13 & 0,11 & 0,10 & 0,09 & 0,09 & 0,08 & 0,09 & 0,09 & 0,10 \\
\hline
\end{tabular}

Fonte: dados da pesquisa. Nota: *Considerando todos os dados da amostra. 


\section{Figura 3 - Evidenciação total média por setor, Brasil e Canadá, 2007-2015}

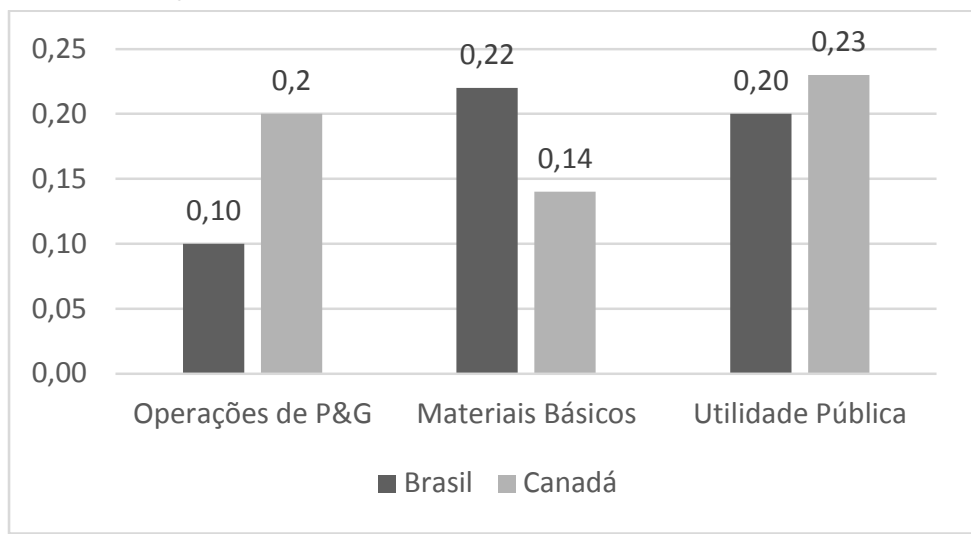

Fonte: Dados da pesquisa.

Os valores referentes à estatística descritiva do ativo total das empresas por país e setor são apresentados na tabela 5. As empresas com maiores ativos encontram-se no setor de Operação de Petróleo e Gás, seguido pelo setor de Materiais Básicos e de Utilidade Pública, tanto no Brasil como no Canadá. A média das empresas brasileira é de $R \$ 80,64$ bilhões, enquanto as canadenses possuem uma média de $R \$ 53,75$ bilhões. No entanto, o desvio padrão brasileiro é maior do que o valor da sua média e cerca de quatro vezes maior que o desvio padrão canadense, indicando uma maior dispersão dos dados.

Tabela 5 - Estatística descritiva do ativo total das empresas, bilhão R\$, 2007-2015

\begin{tabular}{|c|c|c|c|c|c|c|}
\hline País & Setor & Min. & Máx. & Média & $\begin{array}{l}\text { Desvio } \\
\text { Padrão }\end{array}$ & Mediana \\
\hline \multirow{4}{*}{ Brasil } & $\begin{array}{l}\text { Materiais } \\
\text { Básicos }\end{array}$ & 11,62 & 309,42 & 70,07 & 78,21 & 35,58 \\
\hline & $\begin{array}{l}\text { Operação de } \\
\text { P\&G }\end{array}$ & 9,22 & 793,38 & 270,00 & 303,14 & 125,35 \\
\hline & $\begin{array}{l}\text { Utilidade } \\
\text { Pública }\end{array}$ & 8,94 & 163,13 & 34,41 & 40,19 & 20,11 \\
\hline & Total & 8,94 & 793,38 & 80,65 & 144,95 & 27,58 \\
\hline \multirow{4}{*}{ Canadá } & $\begin{array}{l}\text { Materiais } \\
\text { Básicos }\end{array}$ & 8,26 & 36,47 & 25,45 & 25,69 & 8,26 \\
\hline & $\begin{array}{l}\text { Operação de } \\
\text { P\&G }\end{array}$ & 32,56 & 182,67 & 74,58 & 40,75 & 60,29 \\
\hline & $\begin{array}{l}\text { Utilidade } \\
\text { Pública }\end{array}$ & 12,84 & 135,16 & 50,77 & 45,68 & 21,38 \\
\hline & Total & 8,26 & 182,67 & 53,75 & 39,00 & 43,79 \\
\hline \multirow[t]{3}{*}{ Geral } & $\begin{array}{l}\text { Materiais } \\
\text { Básicos }\end{array}$ & 8,26 & 309,42 & 51,33 & 57,55 & 31,28 \\
\hline & $\begin{array}{l}\text { Operação de } \\
\text { P\&G }\end{array}$ & 9,22 & 793,36 & 121,95 & 171,99 & 60,29 \\
\hline & $\begin{array}{l}\text { Utilidade } \\
\text { Pública }\end{array}$ & 8,94 & 163,14 & 37,54 & 41,45 & 20,66 \\
\hline
\end{tabular}

Fonte: Dados da pesquisa.

A mediana das empresas brasileiras ( $R \$ 27,58$ bilhões) está muito distante de sua média. Isso indica que a média brasileira está sendo puxada para cima por algum outlier (do setor de Operação de Petróleo e Gás). Assim, a média 
brasileira é deficiente como medida de tendência central. Em contrapartida, as médias das empresas canadenses são mais bem distribuídas e a mediana do país é mais próxima da média, o que indica uma maior adequação dela como medida de tendência central. Assim, para contornar esse problema, os valores do ativo foram transformados através do logaritmo natural, aproximando os dados da distribuição normal, conforme observa-se na Tabela 6.

\begin{tabular}{|c|c|c|c|c|c|c|}
\hline País & Min. & Máx. & Média & Desvio Padrão & Variância & Mediana \\
\hline Brasil & 9,10 & 13,58 & 10,50 & 0,11 & 0,01 & 10,20 \\
\hline Canadá & 9,02 & 12,12 & 10,62 & 0,76 & 0,58 & 10,69 \\
\hline Total & 9,01 & 13,58 & 10,56 & 0,94 & 0,88 & 10,44 \\
\hline
\end{tabular}

Fonte: Dados da pesquisa.

*Valores correspondem ao logaritmo natural do ativo total.

Foi realizado o teste alfa de Cronbach (1951) para testar a confiabilidade da variável de extensão da evidenciação de RSC, a qual é formada por mais de um indicador. A literatura recomenda que o valor encontrado de alfa seja igual ou superior a 0,70. A extensão da evidenciação é composta por 23 indicadores, divididos em duas dimensões, a ambiental e a social. Essas dimensões obtiveram alfas de 0,8437 e 0,9034 , respectivamente. Ao considerar 0 cálculo com os itens padronizados o alfa foi de 0,8286 para a dimensão ambiental e 0,9109 para a dimensão social. Considerando a dimensão total da evidenciação, formado por todos os 23 indicadores, o alfa encontrado foi de 0,9312 e 0,9327 para itens padronizados.

Com base nos dados dos itens padronizados, foi calculada a confiabilidade das variáveis através do teste de exclusão de itens, que gera novos alfas de Cronbach para a variável caso um dos itens seja excluído. A partir dos resultados percebe-se que na dimensão ambiental, as categorias 1, 7 e 8 (EN2, EN26 e EN28) possuem baixa correlação com os demais itens $(0,2231$, $0,26520,2919$, respectivamente). Além disso, caso não fossem consideradas, a correlação média entre os itens aumentaria, assim como o alfa de Cronbach do indicador. Dessa forma optou-se por desconsiderar esses itens na formação desse indicador. Na dimensão social, as categorias que possuem menor correlação com as demais são a 21 e a 22 (EC3 e EC6). No entanto, optou-se pela não exclusão, pois o novo valor $(0,9147)$ não apresenta grande diferença em comparação ao valor anterior.

\subsection{Análise Hierárquica de Dados}

O modelo hierárquico de dados foi estimado através do método da máxima verossimilhança e identificam a porcentagem da variância dos efeitos aleatórios da evidenciação que pode ser atribuída ao sistema nacional de negócios, ao setor industrial, e aos fatores associados ao desempenho financeiro das empresas. Dessa forma, os modelos testados não se preocupam com os aspectos fixos do modelo (e.g. variáveis independentes e de controle), mas quanto do efeito aleatório pode ser atribuído a cada um dos níveis de agrupamento de dados. Para isso, o modelo decompõe o efeito aleatório em erros relacionados a cada um dos níveis. 
Na tabela 7 são apresentados os modelos testados para a extensão da evidenciação (EV), dividindo a amostra em dados de empresas do Brasil e Canadá. Os resultados indicam que nos anos de 2008 a 2009, as empresas apresentam uma evidenciação semelhante a que foi observada em 2007. Nos anos de 2010 a 2014, as empresas canadenses e brasileiras mantiveram um nível significante de evidenciação e estes valores são superiores ao que foi observado no ano de 2015.

Em seguida, para avaliar quanto dos efeitos aleatórios podem ser atribuídos sistema nacional de negócios, ao setor industrial e aos fatores associados ao desempenho financeiro da empresa, os valores dos efeitos aleatórios de cada um deles foi dividido pelo efeito aleatório total, conforme apresentado na Tabela 8.

Tabela 7 - Modelo hierárquico para a extensão total da evidenciação Efeitos Fixos

\begin{tabular}{c|ccc}
\hline Efeitos fixos & EVT & EVA & EVS \\
\hline 2008 & 0,0008 & 0,0010 & 0,0004 \\
2009 & 0,0114 & 0,0031 & 0,0192 \\
2010 & $0,0356^{* *}$ & $0,0339^{* *}$ & $0,0376^{* * *}$ \\
2011 & $0,0576^{* * *}$ & $0,0625^{* * *}$ & $0,0535^{* * *}$ \\
2012 & $0,0631^{* * *}$ & $0,0750^{* * *}$ & $0,0524^{* * *}$ \\
2013 & $0,0579^{* * *}$ & $0,0810^{* * *}$ & $0,0368^{* * *}$ \\
2014 & $0,0451^{* * *}$ & $0,0615^{* * *}$ & $0,0301^{* *}$ \\
2015 & 0,0112 & 0,0266 & $-0,0024$ \\
Intercepto & $0,1588^{* * *}$ & $0,1760^{* * *}$ & $0,1428^{* * *}$ \\
\hline Teste de Razão de Verossimilhança & $51,90^{* * *}$ & $65,64^{* * *}$ & $35,61^{* * *}$ \\
\hline
\end{tabular}

Fonte: dados da pesquisa.

Nota: Nível de significância: ${ }^{*<0,10 ;}{ }^{* *}<0,05 ;{ }^{* * *}<0,01$.

Tabela 8 - Modelo hierárquico para a extensão total da evidenciação Efeitos Aleatórios

\begin{tabular}{c|ccc}
\hline \multirow{2}{*}{ Efeitos Aleatórios } & \multicolumn{3}{c}{ Variância explicada } \\
\cline { 2 - 4 } & EVT & EVA & EVS \\
\hline Sistema Político & 0,000 & 0,000 & 0,000 \\
Sistema de Trabalho & 0,001 & 0,001 & 0,004 \\
Sistema Financeiro & 0,014 & 0,014 & 0,010 \\
Sistema de Educação & 0,007 & 0,007 & 0,008 \\
Sistema Cultural & 0,000 & 0,000 & 0,000 \\
Intercepto & 0,000 & 0,000 & 0,000 \\
\hline Setor & 0,000 & 0,000 & 0,000 \\
\hline Tamanho & 0,000 & 0,000 & 0,000 \\
ROA & 0,000 & 0,000 & 0,000 \\
Endividamento & 0,006 & 0,006 & 0,002 \\
Intercepto & 0,000 & 0,000 & 0,000 \\
\hline Variância residual & 0,003 & 0,003 & 0,003 \\
\hline
\end{tabular}

Fonte: dados da pesquisa.

Nota: Nível de significância: ${ }^{*}<0,10 ; * *<0,05 ; * * *<0,01$.

A Tabela 9 apresenta a influência dos níveis hierárquicos na extensão da evidenciação de RSC. Os efeitos aleatórios atribuídos aos países representam 71,49\%, os atribuídos às empresas representam 19,41\%, e os relacionados aos 114 Revista Contabilidade Vista \& Revista, ISSN 0103-734X, Universidade Federal de Minas Gerais, 
setores não apresentam percentual significante. Esses resultados mostram que ao analisarmos empresas atuando em países institucionalmente diferentes, o SNN passa a ser o fator preponderante para explicar a evidenciação de RSC. Dentro as dimensões do SNN, o sistema financeiro se destaca na explicação do efeito aleatório da evidenciação de RSC, seguido pelo sistema de educação. O sistema de trabalho se mostra mais representativo na evidenciação da dimensão social quando comparado com a evidenciação da dimensão ambiental.

Analisando, o total explicado pelo nível hierárquico, observa-se a evidenciação (EVT) e a evidenciação da dimensão ambiental (EVA) apresentam um comportamento mais próximo entre si e sofre uma maior influência do endividamento da empresa. Por sua vez, a dimensão social da evidenciação (EVS) parece ser mais influenciada pelo SNN. No caso dos fatores associados ao desempenho financeiro da empresa, o endividamento apresenta uma maior importância para explicar a evidenciação total e, principalmente, a dimensão ambiental. Este indicador está fortemente associado a estrutura de capital, e reflete a facilidade de captação de recursos do mercado de capitais e de crédito.

Tabela 9 - Influência dos níveis hierárquicos na extensão da evidenciação total

\begin{tabular}{|c|c|c|c|c|c|c|c|}
\hline \multirow{2}{*}{$\begin{array}{c}\text { Nível } \\
\text { Hierárquico }\end{array}$} & \multirow[t]{2}{*}{ Dimensão } & \multicolumn{3}{|c|}{ Variância explicada (\%) } & \multicolumn{3}{|c|}{$\begin{array}{c}\text { Total explicado pelo nível } \\
\text { hierárquico }\end{array}$} \\
\hline & & EVT & EVA & EVS & EVT & EVA & EVS \\
\hline \multirow{5}{*}{ SNN } & Sistema Político & $0,00 \%$ & $0,00 \%$ & $0,00 \%$ & \multirow{5}{*}{$71,49 \%$} & \multirow{5}{*}{$71,77 \%$} & \multirow{5}{*}{$82,65 \%$} \\
\hline & $\begin{array}{l}\text { Sistema de } \\
\text { Trabalho }\end{array}$ & $4,24 \%$ & $2,57 \%$ & $15,79 \%$ & & & \\
\hline & $\begin{array}{l}\text { Sistema } \\
\text { Financeiro }\end{array}$ & $44,66 \%$ & $44,95 \%$ & $37,14 \%$ & & & \\
\hline & $\begin{array}{l}\text { Sistema de } \\
\text { Educação }\end{array}$ & $22,59 \%$ & $24,26 \%$ & $29,72 \%$ & & & \\
\hline & $\begin{array}{l}\text { Sistema Cultural } \\
\text { Intercepto }\end{array}$ & $\begin{array}{l}0,00 \% \\
0,00 \%\end{array}$ & $\begin{array}{l}0,00 \% \\
0,00 \%\end{array}$ & $\begin{array}{l}0,00 \% \\
0,00 \%\end{array}$ & & & \\
\hline \multirow{4}{*}{ Empresa } & Tamanho & $0,00 \%$ & $0,00 \%$ & $0,00 \%$ & \multirow{4}{*}{$19,41 \%$} & \multirow{4}{*}{$19,26 \%$} & \multirow{4}{*}{$6,80 \%$} \\
\hline & $\mathrm{ROA}$ & $0,00 \%$ & $0,00 \%$ & $0,00 \%$ & & & \\
\hline & Endividamento & $19,41 \%$ & $19,26 \%$ & $6,80 \%$ & & & \\
\hline & Intercepto & $0,00 \%$ & $0,00 \%$ & $0,00 \%$ & & & \\
\hline Setor & $\begin{array}{l}\text { Setor de } \\
\text { atuação }\end{array}$ & $0,00 \%$ & $0,00 \%$ & $0,00 \%$ & $0,00 \%$ & $0,00 \%$ & $0,00 \%$ \\
\hline Resíduo & $\begin{array}{l}\text { Variância } \\
\text { residual }\end{array}$ & $9,09 \%$ & $8,97 \%$ & $10,55 \%$ & $9,09 \%$ & $8,97 \%$ & $10,55 \%$ \\
\hline
\end{tabular}

Fonte: Dados da pesquisa.

Com base nos resultados, apoiam-se as hipóteses $\mathrm{H}_{1}$ e $\mathrm{H}_{2}$ em todas as dimensões avaliadas. Os resultados indicam que o sistema nacional de negócios é capaz de explicar o maior percentual da variabilidade da evidenciação de RSC nas empresas do Brasil e Canadá, seguido dos fatores associados ao desempenho financeiro. O setor industrial mostra-se irrelevante para explicar a evidenciação de práticas de RSC, em um contexto multinível. 


\section{DISCUSSÃO}

Os resultados da análise hierárquica de dados identificam que a porcentagem da variância dos efeitos aleatórios impactando na extensão da evidenciação pode ser atribuída aos níveis do país e da empresa. Estes resultados somados com os da estatística descritiva, que mostram uma maior divulgação da RSC brasileira em comparação com a canadense, e informações sobre o ambiente institucional do Brasil e do Canadá (WEF, 2015; UNDP, 2017; WORLD BANK, 2015) indicam que um ambiente institucional menos desenvolvido levam as empresas a divulgarem mais informações de RSC.

Este resultado corrobora com os trabalhos de Abreu et al., (2015) e Soares et al (2018) que confirmam a influência do ambiente institucional do Brasil nas práticas de RSC. Países em desenvolvimento, possuem limites turvos nos SNN, e usam a evidenciação como um meio para facilitar a captação de recursos financeiros. Neste sentido, Damiano-Teixeira e Pompermayer (2007) reforçam que as empresas no Brasil estão se tornando mais ativas em lidar com questões sociais e ambientais para se afastarem da imagem de corrupção e acumulação de riquezas.

Para Thorne, Mahoney, Gregory e Convery (2017), as empresas canadenses, devido à força exercida pelo ambiente institucional, se engajam em práticas de RSC voluntárias e alianças estratégicas em resposta às pressões dos stakeholders para que elas hajam de modo correto. Os países desenvolvidos têm um claro conjunto de parâmetros e limites que orientam as respostas de RSC, o que se traduz em uma "RSC implícita" (MATTEN; MOON, 2008), e que a evidenciação de práticas ambientais e sociais seja mais limitada.

Os resultados para o nível do setor podem ser justificados pela escolha para compor a amostra, apenas aqueles considerados como ambientalmente sensíveis. No caso da influência dos fatores associados ao desempenho financeiro, o trabalho atende a crítica proposta por Margolis e Walsh (2003) e confirma o papel discricionário dos gestores na alocação de recursos financeiros para tratar de questões ambientais e sociais.

A maior importância dada ao sistema financeiro, dentro do SNN, e ao endividamento, dentro das características financeiras da empresa, se alinha com o que é defendido por Gainet (2010), uma vez que para o autor, a folga financeira de uma empresa é capaz de influenciar o nível de adoção de práticas de RSC. Para Arora e Dharwadkar (2011), a existência de uma "almofada de recursos" (i.e. uma folga financeira), provê à empresa a oportunidade de investir em causas sociais e também reduz sua resistência a atender às demandas dos stakeholders.

Os resultados da pesquisa contradizem (em parte) o que foi encontrado por Orlitzky et al. (2017), quando encontrou que os fatores organizacionais são mais importantes do que fatores ligados ao setor e ao ambiente institucional na determinação do desempenho social corporativo. Cabe destacar, que os autores partem da ideia de que devido ao fato das forças ligadas ao SNN não atuarem de modo necessariamente homogêneo no que tange à organização interna das empresas, isso reduz a importância do ambiente institucional para a 
explicação de práticas de RSC adotadas pelas empresas, quando são levadas em consideração as características da firma.

Para confirmar sua hipótese, Orlitzky et al. (2017) avalia a influência de variáveis associadas ao SNN, ao setor e à firma, para a explicação das práticas de RSC de uma amostra com 2.060 empresas, em um painel balanceado de cinco anos (2003 a 2007), em 21 países, sendo 19 deles membros da União Europeia, além dos Estados Unidos e da Coreia do Sul. Os autores mostram que, de modo geral, as variáveis no nível da firma são os principais determinantes para a extensão de RSC das empresas. Nesse sentido, Soares et al. (2018) sugerem que as características do sistema financeiro são determinantes na evidenciação em países emergentes, quando comparadas a empresas em países desenvolvidos

\section{CONCLUSÃO}

A pesquisa permitiu identificar a importância do sistema nacional de negócios na evidenciação de práticas ambientais e sociais em empresas atuando em países com características institucionais distintas. No campo gerencial, os resultados do trabalho indicam aos gestores que fatores externos à firma e associados ao desempenho financeiro são capazes de influenciar a extensão da evidenciação requerida pelos stakeholders. No campo teóricoempírico, a pesquisa reforça o uso da teoria institucional em estudos sobre evidenciação. Neste sentido, um ambiente institucional eficiente possibilita um diálogo com os investidores, com vista a incorporação de ações socialmente responsáveis. Este processo deve reconhecer as interconexões do campo organizacional com o contexto institucional.

O estudo possui limitações que devem ser reconhecidas. Primeiramente, devido a indisponibilidade de relatórios de sustentabilidade, nos sites das empresas, anteriores ao ano de 2007. Esse fato também levou a uma redução do tamanho da amostra. Foram selecionados setores ambientalmente sensíveis e que apresentassem um número similar de observações entre empresas nos dois países. Outrossim, o número de observações foi menor do que o esperado, devido às fusões de empresas.

Embora se reconheçam limitações empíricas, este trabalho contribui para a pesquisa sobre evidenciação de RSC. Utiliza modelagem hierárquica linear e contribui com a necessidade de os gestores avaliarem a influência das características que moldam o sistema nacional de negócios e o desempenho financeiro na definição de estratégias relacionadas à evidenciação de responsabilidade social corporativa.

\section{AGRADECIMENTOS}

A Editora e aos Revisores Anônimos por suas valiosas contribuições para a melhoria da versão inicial do artigo e ao CNPq pelo financiamento ao Projeto de Pesquisa. 


\section{REFERÊNCIAS}

ABREU, M. C. S.; CUNHA, L. T.; BARLOW, C. Y. Institutional dynamics and organizations affecting the adoption of sustainable development in the United Kingdom and Brazil. Business Ethics: A European Review, v. 24 n. 1, p. 73-90, 2015.

ARORA, P.; DHARWADKAR, R. Corporate governance and corporate social responsibility (CSR): the moderating roles of attainment and organization slack. Corporate Governance: An International Review, v. 19, n. 2, p. 136-152, 2011.

BEWLEY, K.; LI, Y. Disclosure of environmental information by Canadian manufacturing companies: A voluntary disclosure perspective. In: JAGGI, B.; FREEDMAN, M. (ed.). Advances in Environmental Accounting \& Management. Emerald Group Publishing Limited, 2000

BROOKES, M.; BREWSTER, C.; WOOD, G. Social relations, firms and society: a study of institutional embeddedness. International Sociology, v. 20 n. 4, p. 403-426, 2005

CAMPBELL, J. L. Institutional analysis and the paradox of corporate social responsibility. American Behavioral Scientist, v. 49, n. 7, p. 925-938, 2006.

CAMPBELL, J. L. Why would corporations behave in socially responsible ways? An institutional theory of corporate social responsibility. Academy of Management Review, v. 2 n. 3, p. 946-967, 2007.

CARROLL, A. B. The pyramid of corporate social responsibility: toward the moral management of organizational stakeholders. Business Horizons, v. 34 n. 4, p. 3948, 1991.

CARROLL, A. B. A history of corporate social responsibility: concepts and practices. In: Crane, A.; Mcwilliams, A.; Matten, D.; Moon, J.; Siegel, D. (Eds.) The Oxford handbook of corporate social responsibility. Oxford University Press: Inglaterra, 2008.

CHAUHAN, S.; AMIT, A relational study of firm's characteristics and CSR expenditure. Procedia Economics and Finance, v. 11, p. 23-32, 2014.

CONCEIÇÃO, S. H., DOURADO, G. B., BAQUEIRO, A. G., FREIRE, S.; BRITO, P. C. Fatores determinantes no disclosure em Responsabilidade social corporativa (RSC): um estudo qualitativo e quantitativo com empresas listadas na Bovespa. Gestão \& Producãá, v. 18 ก. 3, 461-472, 2011.

CRONBACH, L. J. Coefficient alpha and the internal structure of tests. Psychometrika, v. 6 n. 8, P. 297-334, 1951.

CORDEIRO, J. J. \& TEWARI, M. Firm characteristics, industry context, and investor reactions to environmental CSR: a stakeholder theory approach. Journal of Business Ethics, v. 130 n. 4, p. 833-849, 2015.

DAMIANO, K. M. T.; POMPERMAYER, M. M. Corporate Social Responsibility: Profile and Diagnosis of 797 Programs Developed in Brazil. Business and Society Review. v. 112 n. 3, p. 343-367, 2007.

DELMAS, M. A. The diffusion of environmental management standards in Europe and in the United States: an institutional perspective. Policy Sciences, v. 35, p. 91$119,2002$. 
EUROPEAN COMMISSION. ABC of the main instruments of Corporate Social Responsibility. Luxembourg: Office for Official Publications of the European Communities, 2004.

FIFKA, M. S. Corporate responsibility reporting and its determinants in comparative perspective: a review of the empirical literature and a metaanalysis. Business Strategy and the Environment, v. 22, n. 1, 1-35, 2013.

FISCHER, T. M.; SAWCZYN, A. A. The relationship between corporate social performance and corporate financial performance and the role of innovation: evidence from German listed firms. Journal of Management Control, 24(1), 27-52, 2013.

GAINET, C. Exploring the impact of legal systems and financial structure on corporate responsibility. Journal of Business Ethics, v. 95, p; 195-222, 2010.

GÓIS, A. D.; DE LUCA; M. M. M.; VASCONCELOS, A. C. Determinantes da divulgação dos indicadores de desempenho da GRI nas empresas do Brasil e da Espanha. Revista Ambiente Contábil, v. 7, n. 1, p. 155 - 175, 2015

GOLOB, U.; BARTLETT, J. L. Communicating about corporate social responsibility: a comparative study of CSR reporting in Australia and Slovenia. Public Relations Review, v. 33, n. 1, p. 1-9, 2007.

GONÇALVES, R. S. Social disclosure e custo de capital próprio em empresas brasileiras de capital aberto. (Tese de Doutorado em Ciências Contábeis). 2011. Universidade de Brasília, BR, 2011.

GRECCO, M. C.; MILANI FILHO; M. A.; SEGURA, L., SANCHEZ; I. M.; DOMINGUEZ, L. The voluntary disclosure of sustainable information: a comparative analysis of Spanish and Brazilian companies. Revista de Contabilidade e Organizações, v. 7 , n.17, p. 45-55, 2013.

GRI. Diretrizes para relatórios de sustentabilidade, versão 3.1, 2011. Recuperado de https://www.globalreporting.org/resourcelibrary/Brazilian-PortugueseG3.1.pdf

HO, L. J.; TAYLOR, M. E. An empirical analysis of triple bottom-line reporting and its determinants: evidence from the United States and Japan. Journal of International Financial Management and Accounting, v. 18, n.2, 2007.

HOU, J.; REBER, B. H. Dimensions of disclosures: corporate social responsibility (CSR) reporting by media companies. Public Relations Review, v. 37, n. 2, p. 166$168,2011$.

IDEMUDIA, U. Corporate social responsibility and developing countries: moving the critical CSR research agenda in Africa forward. Progress in Development Studies, v. 11, n. 1, P. 1-18, 2011.

IOANNOU, I; SERAFEIM, G. What drives corporate social performance? The role of nation-level institutions. Journal of International Business Studies, 43(9), 834-864, 2012.

JAIN, N.; MISHRA, S. S. Firm characteristics and CSR rating: empirical evidence from India. In: KARVE, S.; GAWDE, R.P. (eds). Corporate social responsibility: issues and challenge, Allied Publishers, p. 341-350, 2011. 
JAMALI, D. CSR in developing countries through an institutional lens. Critical Studies on Corporate Responsibility, Governance and Sustainability, v. 8, p. 21-44, 2014.

JAMALI, D.; MIRSHAK, R. Corporate social responsibility (CSR): theory and practice in a developing country context. Journal of Business Ethics, v. 72 n. 3, p. 243-262, 2007.

JONES, M. T. The Institutional determinants of social responsibility. Journal of Business Ethics, v. 20, n. 2, p. 163-179, 1999.

KARAM, C. M.; JAMALI, D. Gendering CSR in the Arab Middle East: an institutional perspective. Business Ethics Quarterly, v. 23, n. 1, p. 31-68, 2015.

KOLK, A.; LENFANT, F. MNC reporting on CSR and conflict in Central Africa. Journal of Business Ethics, v. 93, p. 241-255, 2010.

MAROCO, J.; GARCIA-MARQUES, S. A. (2006). Qual a fiabilidade do alfa de Cronbach? Questões antigas e soluções modernas? Laboratório de Psicologia, v. 4, n. 1, p. 65-90, 2006.

MATTEN, D.; MOON, J. "Implicit" and "explicit" CSR: a conceptual framework for a comparative understanding of corporate social responsibility. Academy of Management Review, v. 33 n. 2, p. 404-424, 2008.

MCWILLIAMS, A.; SIEGE, D. S.; WRIGHT, P. M. Corporate social responsibility: strategic implications. Journal of Management Studies, v. 43, n. 1, p. 1-18, 2006.

MICHELON, G.; PILONATO, S.; RICCERI, F. CSR reporting practices and the quality of disclosure: An empirical analysis. Critical Perspectives on Accounting, v. 33, p. 59-78, 2015.

MOON, J.; SHEN, X. CSR in China research: salience, focus and nature. Journal of Business Ethics, v. 94, P. 613-629, 2010.

MUTTAKIN, M. B.; KHAN, A.; SUBRAMANIAM, N. Firm characteristics, board diversity and corporate social responsibility: evidence from Bangladesh. Pacific Accounting Review, v. 27, n. 3, p. 353 - 372, 2015.

NATIS, L. Modelos lineares hierárquicos. Estudos em Avaliação Educacional, v. 3, 2001.

ORLITZKY, M.; LOUCHE, C.; GOND, J.-P.; CHAPPLE, W. Unpacking the drivers of corporate social performance: a multilevel, multistakeholder, and multimethod analysis. Journal of Business Ethics, v. 144, n. p. 1, 21-40, 2017.

PARSA, S.; KOUHY, R. Social reporting by companies listed on the alternative. Journal of Business Ethics, v. 79, n. 3, 345-360, 2008.

SOARES, R. A.; PINHEIRO, A. B.; ABREU, M. C. S.; MARINO, P. B. L. P. Efeito do sistema financeiro na evidenciação socioambiental de empresas em países emergentes e desenvolvidos. Enfoque: Reflexão Contábil (Impresso), v. 37, p. 21 35, 2018.

TANG, L.; LI, H. Corporate social responsibility communication of Chinese and global corporations in China. Public Relations Review, v. 35, n. 3, p. 199-212, 2009.

TEMPEL, A.; WALGENBACH, P. Global standardization of organizational forms and 
management practices? What new institutionalism and the business-systems approach can learn from each other. Journal of Management Studies, v. 44, n. 1 , 1-24, 2007.

WORLD BANK. Worldwide Governance Indicators, 2016. Recuperado de http://info.worldbank.org/governance/wgi/index.aspx\#home

THORNE, L.; MAHONEY, L. S.; GREGORY, K.; CONVERY, S. A Comparison of Canadian and U.S. CSR Strategic Alliances, CSR Reporting, and CSR Performance: Insights into Implicit-Explicit CSR. Journal of Business Ethics, v. 143, n. 1, p. 85-98, 2017.

TSCHOPP, D., WELLS, S; BARNEY, D. The institutional promotion of corporate social responsibility reporting. The Journal of Academic and Business Ethics, v. 12, p. 117, 2012.

UNDP. Human Development Report. 2017. Recuperado de http://hdr.undp.org.

WEF. WORLD ECONOMIC FORUM. The global competitiveness report. 2015-2016. World Economic Forum, 2015

WHITLEY, R. Divergent Capitalisms: the social structuring and change of business systems. Oxford: Oxford University Press, 1999.

WHITLEY, R. How national are business systems? The role of different state types and complementary institutions in constructing homogenous systems of economic coordination and control. Workshop on National Business Systems in the New Global Context, Oslo, 2003

YANG, H. H., GRAIG, R., \& FARLEY, A. A Review of Chinese and English language studies on corporate environmental reporting in China. Critical Perspectives on Accounting, v, 28, p. 30-48, 2015. 